\title{
SEGREGAÇÃO, ESCOLA E DESIGUALDADES: RACIALIZANDO AS OPORTUNIDADES EDUCACIONAIS
}

\section{SEGREGATION, SCHOOL AND INEQUALITIES: RACIALIZING EDUCATIONAL OPPORTUNITIES}

\author{
RAUL, Jessica M. ${ }^{1}$ \\ RODRIGUES, Jose Roberto da Silva²
}

\begin{abstract}
RESUMO
Este artigo objetiva uma análise racializada do fenômeno da segregação residencial para a reprodução das desigualdades educacionais na cidade do Rio de Janeiro. Entendemos que tanto a segregação socioespacial, quanto as relações humanas estabelecidas em um mundo hierarquizado a partir de pressupostos raciais tem efeitos negativos para os que estão nela envolvidos, com maior prejuízo para população negra porque, além de lhe causar danos psíquicos, se materializam em suas vidas gerando uma condição de subalternidade (OLIVEIRA, 2012). Examinaremos, à luz da pedagogia, o tema da segregação, partindo da reflexão sobre o território e suas implicações para a efetivação de direitos como educação, considerando a particularidade da segregação carioca, que, para além padrão núcleoperiferia, é marcada também por uma proximidade física e distância social.
\end{abstract}

PalavRAS-ChaVe: Segregação Residencial; Oportunidades Educacionais; Rio de Janeiro.

\begin{abstract}
This article aims at a race related analysis of the phenomenon of residential segregation for the reproduction of educational inequalities in Rio de Janeiro. We understand that sociospatial segregation and human relations established in a hierarchical world based on racial assumptions have negative effects for everyone involved. Greater damage, however, is for the black population because, in addition to causing psychical harm, it affects their lives generating a condition of subalternity (OLIVEIRA, 2012). We address here, in the light of pedagogy, the theme of segregation, starting from the reflection on territory and its implications for the realization of rights as education. Considered also is the particularity of segregation in Rio de Janeiro, which, besides the core-periphery pattern, is also marked by physical proximity and social distance.
\end{abstract}

KEYWORDS: Residential Segregation; Educational Opportunities; Rio de Janeiro.

\footnotetext{
${ }^{1}$ PPRER/CEFET-RJ. e-mail: jraul.prof@gmail.com

2 Professor Adjunto da Universidade do Estado do Rio de Janeiro - CAp-UERJ. e-mail: zrsrodrigues@yahoo.com.br
} 


\section{RIO DE JANEIRO E DESIGUALDADES: DO SOCIORRACIAL AO SOCIOESPACIAL}

Pensar a segregação socioespacial, considerando a divisão racial do território carioca e a particularidade da segregação carioca significa reconhecer que as desigualdades sociorraciais reproduzem-se também no âmbito da divisão territorial. Esse pressuposto é plausível se considerarmos a historicidade das desigualdades na sociedade brasileira.

Assim, a reflexão sobre uma sociedade racializada e seus desdobramentos para o acesso a bens sociais, considerando que estas interferem também no contexto intraescolar, pode contribuir com reflexões que possibilitem pensar políticas públicas que facilitem a geração de equidade na qualidade de ensino nas diferentes áreas da cidade, assim como para a compreensão da dinâmica entre a escola e o espaço urbano.

O recorte racial das nossas proposições visa verificar o maior nível de desigualdade na sociedade brasileira, buscando a compreensão tanto dos processos de produção de desigualdades quanto de possibilidades de promoção de equidade. Racializar as desigualdades faz parte de um projeto que contempla uma perspectiva humanista de construção social, essencial para a superação das desigualdades sociorraciais. Para tanto, compreender as construções históricas que fundamentaram as desigualdades é um dos caminhos possíveis para transpor as barreiras impostas pelos estereótipos à efetivação da cidadania em parcelas marginalizadas da população.

As diferenças estabelecidas enquanto ferramentas de hierarquização dos seres humanos, base para a mentalidade colonial, colocou a população negra na base da pirâmide social representando barreiras ao direito à cidade ${ }^{3}$ e à cidadania na medida em que se estabelecia pela lógica hierarquizante na aquisição de bens sociais. Para compreender como as desigualdades perpetuaram, devemos partir de sua construção e difusão como um fator natural aos grupos humanos que, de acordo com Quijano (2005), centrou-se na ideia de raça e outorgou legitimidade às relações de dominação impostas pela conquista colonial.

\footnotetext{
${ }^{3}$ Desenvolvido por Henri Lefebvre (2001), o conceito de direito à cidade, para ele, "não pode ser concebido como um simples direito de visita ou de retorno às cidades tradicionais. Só pode ser formulado como direito à vida urbana, transformada, renovada" (LEFEBVRE, 2001, p. 117-118). Seria o direito de não exclusão da sociedade urbana como recuperação desse espaço pelos grupos marginalizados, se manifestando como forma superior dos direitos: à liberdade, à individualização na socialização, ao habitat e ao habitar. O direito à obra (a atividade participante) e o direito a apropriação (bem distinto do direito à propriedade) estão implicados no direito à cidade (LEFEBVRE, 2001, grifos do autor). Já para Harvey (2013), o direito à cidade é muito mais que a liberdade individual de ter acesso aos recursos urbanos: é um direito de mudar a nós mesmos, mudando a cidade. Além disso, é um direito coletivo, e não individual, já que essa transformação depende exercício de um poder coletivo para remodelar os processos de urbanização. A liberdade de fazer e refazer as nossas cidades, e a nós mesmos, é, a meu ver, um dos nossos direitos humanos mais preciosos e ao mesmo tempo mais negligenciados.
} 


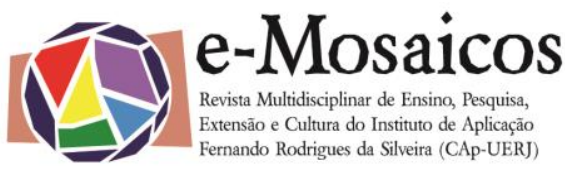

DOI: $10.12957 /$ e-mosaicos.2018.33623

Para o autor, a elaboração da perspectiva eurocêntrica como naturalização dessas relações de dominação entre europeus e não-europeus significou uma nova maneira de legitimar a superioridade/inferioridade entre dominadores e dominados e o mais eficaz instrumento de dominação. Assim, "raça converteu-se no primeiro critério fundamental para a distribuição da população mundial nos níveis, lugares e papéis na estrutura de poder da nova sociedade" (QUIJANO, 2005, p. 118).

As diferenças foram utilizadas como ferramentas de hierarquização baseada na permanência de uma mentalidade colonial, e os negros foram aprisionados na base da pirâmide social. Portanto, "a reflexão sobre a sociedade colonial e o paradigma moderno do qual ela faz parte nos remete às suas consequências de longa duração para a manutenção e perpetuação das desigualdades" (RAUL, 2016).

Nesse sentido, o período colonial deve ser encarado como um período de disputa em que, mesmo em condições de subordinação, é fundamental considerar as articulações estabelecidas entre a população negra e que teve como consequências a criação, pela elite branca colonial, de uma série de mecanismos ainda mais cruéis, necessários a contemporização das estratégias de dominação garantidoras de políticas excludentes e de desarticulação da população afro-brasileira.

Tendo em vista que "a manutenção das desigualdades está diretamente relacionada ao acesso ao trabalho e que distribuição de recursos na sociedade é profundamente marcada pela condição de raça e gênero dos indivíduos" (SILVA, 2013, p. 109), podemos, a partir da análise de Pelegrino (2006), verificar que essas hierarquias determinam as possibilidades de acesso a bens materiais. Além disso, ao verificar os dados pelo corte de raça/cor, relacionado ao sexo, pode-se notar a manutenção das barreiras que colocam as mulheres negras na base da pirâmide social, evidenciando-se a relação entre inserção precoce no mercado de trabalho, subemprego e baixa escolaridade na qual as mulheres negras amargam os piores índices.

Desigualdades essas que se manifestam também na apropriação e reprodução do espaço urbano, baseado em uma racionalidade capitalista, que nasce e se desenvolve fortemente atrelada à hierarquização racial forjada nesse período. Assim, as estratégias de manutenção do status quo da elite branca nacional se utilizaram de estereótipos sobre as populações como forma de controle que justificavam as intervenções no solo urbano, seja pelo discurso higienista ou a retórica do medo ${ }^{4}$, alocando - através de variadas intervenções e reformas - as pessoas no espaço de acordo com o poder aquisitivo.

Para Novaes (2014, p. 13),

Desigualdade diz respeito à distribuição desequilibrada de recursos coletivos e à exposição desproporcional aos problemas decorrentes

\footnotetext{
${ }^{4}$ Sobre esse tema ver Chaloub 1996, 2001, 2011), Campos (2007) e Fernandes (2005).
} 
das práticas sociais. Tomada como fenômeno social, e não como medida, evidencia um caráter sistêmico: tende a se perpetuar graças à superposição de formas variadas de desigualdade que contribuem para renovar os obstáculos associados às posições da hierarquia social.

Ainda segundo Novaes (2014), a produção do espaço resulta de ações realizadas a partir de lugares distintos na hierarquia social. Trata-se de processo disputado, com frequência desequilibrado, visto que os agentes têm condições desiguais para impor os seus interesses. Nesse processo, oposições no espaço social são traduzidas ou transplantadas - embora de modo imperfeito - para o espaço físico. Diferenças e desigualdades sociais manifestam-se espacialmente na distribuição desuniforme de serviços públicos e de infraestrutura.

Através da história, "a cidade tem sido um espaço criado e transformado, sobretudo pelas classes dominantes" (RODRIGUES, 2005, p. 128), e o Rio de Janeiro é um exemplo dessa diferenciação, emblemático para pensar, inclusive, o nascimento do capitalismo no Brasil, pois a integração do país ao sistema mundial corresponde à necessidade de modernizar a cidade, então capital federal, e a adequação do espaço urbano às necessidades do capital, que redefiniu os usos do solo urbano e se concretizou com a derrubada dos cortiços e a expulsão das populações pobres da área central da cidade.

Aos negros e negras era cerceada a oportunidade de atuar no mercado de trabalho, e a Lei de Terras, de 1850, foi um obstáculo ao seu acesso à propriedade da terra. Já na época das reformas urbanísticas do prefeito Pereira Passos, Sidney Chalhoub nos fala que um aspecto fundamental da vida cotidiana do pobre urbano da cidade do Rio de Janeiro era o problema da moradia (CHALHOUB, 2001).

Se pensarmos na articulação entre território e a questão racial, podemos sugerir que a população negra, concentra-se em espaços específicos na cidade, a saber, em favelas e periferias. Rolnik (1989), ao tratar dos territórios negros nas cidades brasileiras, procura demonstrar que existe um território negro específico nessas cidades. A autora ressalta que tal quadro é perfeitamente plausível e nos mostra que a história do Rio de Janeiro e a de São Paulo é marcada pela marginalização e estigmatização do território negro. Para ela, no Rio de Janeiro, a luta pela apropriação do solo urbano acabou por consolidar as favelas como os espaços mais caracterizadamente negros da cidade. No mesmo sentido, para Andrelino Campos (2007), uma das possibilidades para se compreender a favela é trabalhar com a ideia de um espaço transmutado, do Quilombo à Favela.

Portanto, partiremos de uma reflexão que relaciona este território marginalizado e os desafios de implementação de direitos nesses espaços, como educação de qualidade, considerando a particularidade da segregação carioca, que não só se caracteriza pelo padrão núcleo-periferia, mas conta com a existência de 


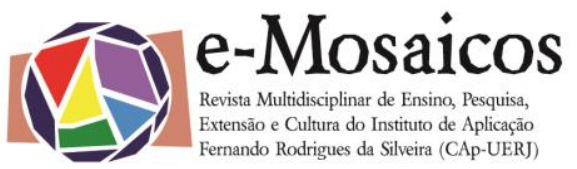

DOI: $10.12957 /$ e-mosaicos.2018.33623

favelas espalhadas por todo o tecido urbano, além da existência de outra forma de organização, caracterizada por uma proximidade física e distância social.

Assim, tanto a segregação socioespacial quanto as relações humanas estabelecidas em uma sociedade hierarquizada a partir de pressupostos raciais, têm efeitos negativos para os que estão nela envolvidos e tais efeitos são mais evidentes na população negra porque, além de lhe causar danos psíquicos, se materializam-se em suas vidas gerando uma condição de subalternidade (OLIVEIRA, 2012).

De acordo com o IPEA (2011), a distribuição de domićlios urbanos, segundo sexo e cor/raça do/da chefe familiar, em 2009, no Brasil correspondem a 2 milhões de domicílios, no qual 33,9\% possuem chefia branca, e por volta de $66 \%$ apresentam chefia negra. Esses dados são significativos para se pensar nas condições de vida dos sujeitos a serem investigados e nos levam ao entendimento de que este grupo está submetido a uma maior vulnerabilidade social.

Pensar o papel transformador da educação implica em pensar na necessidade de garantir paridade de oportunidades entre os habitantes dos diversos locais. Nesta realidade, é importante refletir sobre o processo no qual a cidade se torna palco de investimentos, mas que não necessariamente são revertidos em melhores condições de vida da população mais vulnerável econômica e socialmente, onde "há uma contradição dialética entre capital e cidade, entre capital e espaço urbano, que se materializa nas práticas sociais, no exercício da cidadania" (CAVALCANTI, 2008, p. 70).

Diante desse panorama, "a concentração territorial dos segmentos vulneráveis transforma-se em segregação residencial, em isolamento físico, sociocultural e dos direitos cívicos e políticos inerentes à condição urbana" (RIBEIRO; KAZTMAN, 2008, p. 16), tornando-se necessária a sua compreensão para forjar estratégias de superação.

A partir do reconhecimento de que os vários contextos sociais da cidade interferem no desempenho escolar e o papel que os estereótipos têm na relação professor/aluno, o tema da democratização da educação, em suas várias faces, abre espaço para pensar a cidade em seus diversos aspectos, possibilitando entender a relação entre Segregação Socioespacial, Educação e Cidadania.

\section{OPORTUNIDADES EDUCACIONAIS EM UM RIO DE JANEIRO RACIALIZADO}

De forma geral, são inegáveis os avanços conquistados pela população brasileira na área da educação (SILVA, 2012), mas essas conquistas não se traduziram em equidade de oportunidades para os segmentos mais vulneráveis. Assim, torna-se necessária a busca pela diminuição das desigualdades raciais, regionais e de gênero, que transpassa toda a sociedade brasileira. Aqui, para fins de análise, será priorizado o recorte racial na tentativa de compreensão do fenômeno da 
DOI: $10.12957 /$ e-mosaicos.2018.33623

segregação socioespacial em uma das cidades mais negras do Brasil, o Rio de Janeiro.

As desigualdades sociorraciais e espaciais acarretam ainda em desigualdades educacionais. Ribeiro (2012), ao refletir sobre a escolarização da população negra, apoiada no Relatório do Presidente da Província de 1872, nos mostra que "o número diminuto de escolas e a má localização das mesmas dentro dos municípios fluminenses exigem medidas enérgicas" (RIBEIRO, 2012, p. 233).

A mobilidade no Brasil nos seus "anos dourados" (entre 1930 a 1970) ou no decorrer dos anos 80, de acordo com Telles (2009), não foi determinante para o destino ocupacional da maioria dos brasileiros que, apesar de encaminhar os jovens mais escolarizados para posições superiores vem, durante, pelo menos, os últimos 25 anos bloqueando as possibilidades de ascensão social da população mais pobre. Para a autora, "as melhorias educacionais das últimas décadas não se traduziram em melhores posições no mercado de trabalho" (TELLES, 2009, p. 168).

Se considerarmos que a educação brasileira "não capacita os cidadãos em igualdade de condições, tão pouco leva em consideração suas diferenças" (MANCEBO, 2009, p. 176) conseguiremos entender a estrutura perversa de manutenção das desigualdades escolares. Ainda, tendo como base estudos como 0 de Costa (2012, p. 267) que afirmam que "estudos sobre cotidiano escolar que têm como objeto central as relações raciais evidenciam um contexto escolar desfavorável à população negra", considero necessária, portanto, a realização de uma investigação racializada das desigualdades escolares e das possíveis implicações dos estereótipos, que para além de se constituírem enquanto construções com implicações no direito à cidadania interferem também no contexto escolar.

Os vários âmbitos da desvantagem da população afro-brasileira em relação à aquisição de bens sociais não cabem ser pormenorizadas nesta tentativa reflexiva, no entanto, podemos aqui entender como essenciais as políticas de promoção da igualdade racial. Especialmente no caso das desigualdades sociorraciais e espaciais, devemos entendê-las como interligadas no sentido de sua incisiva interferência no cotidiano escolar.

\section{CONSIDERAÇões FinaIS}

Assim, consideramos aqui, como um ponto primordial a ser debatido, que os efeitos da segregação socioespacial atuam como um dos entraves para a geração de equidade educacional. Nossa análise subentende também a importância do reconhecimento destas questões como parte da realidade do aluno, desdobrando-se na necessidade de investigar mecanismos para o enfrentamento das diversas problemáticas geradas nessas realidades no contexto escolar. 
DOI: $10.12957 /$ e-mosaicos.2018.33623

O recorte racial nessa análise pretende verificar as desigualdades em sua face extrema, como no caso de estudantes negros oriundos das classes populares de territórios marginalizados.

Considerado aqui como um ponto primordial a ser debatido, os efeitos da segregação socioespacial como um dos entraves para a geração de equidade educacional, sua análise subentende também a importância do seu reconhecimento como parte da realidade do aluno, com desdobramentos na necessidade de investigar mecanismos para o enfrentamento de suas consequências no contexto escolar.

Nesse sentido, permanências históricas retrógradas (mas não imutáveis) estão em detrimento de direitos humanos fundamentais, como no caso da educação e do direito à cidade. De acordo com Nilma Lino Gomes (2012), vivemos, um momento ímpar no campo do conhecimento, em que o debate sobre a diversidade epistemológica do mundo encontra maior espaço nas ciências humanas e sociais (GOMES, 2012:99), tornando possível um outro fazer historiográfico, talvez não tão coerente e homogêneo, mas desconfiada dos lugares comuns estabelecidos.

Por isso, o impulso de (re)construção da memória ganha força, atentando sobre "o perigo de uma história única", nas palavras de Chimamanda Adichie, importante por trazer à tona a necessidade de outras vozes na escrita da História, o que é uma das possibilidades de entender o cerne das desigualdades que impedem o pleno exercício da cidadania nas diferentes áreas da cidade e um caminho para a construção de identidades para além de estereótipos na edificação de uma sociedade cada vez menos desigual.

\section{REFERÊNCIAS}

CAMPOS, Andrelino. Do quilombo à favela: a produção do "espaço criminalizado" no Rio de Janeiro. $2^{\circ}$ ed. Rio de Janeiro: Bertrand Brasil, 2007.

CAVALCANTI, Lana de Souza. A geografia escolar e a cidade: ensaios sobre o ensino de geografia para a vida urbana cotidiana. Campinas, SP: Papirus, 2008 (Coleção Magistério: Formação e Trabalho Pedagógico).

CHALHOUB, Sidney. Cidade Negra. In: Visões da Liberdade: Uma história das últimas décadas da escravidão na Corte. São Paulo: Companhia das Letras, 2011. pp. 218265.

COSTA, Candida Soares da. Currículo, relações étnico-raciais e os fundamentos teóricos da educação escolar. In: OLIVEIRA, Iolanda (Org.). Relações raciais no contexto social, na educação e na saúde: Brasil, Cuba, Colômbia e África do Sul. Rio de Janeiro: Quartet, 2012. 
DOI: $10.12957 /$ e-mosaicos.2018.33623

KOSLINSLI, Mariane; e ALVES, Fátima. Novos olhares para as desigualdades de oportunidades educacionais: a segregação residencial e a relação favela-asfalto no contexto carioca. In: Educação e Sociedade. Campinas, v. 33, n. 120, 2012. pp. 805831. Disponível em < http://www.cedes.unicamp.br >. Consulta em 03/07/2016.

LIMA, Leonardo Claver Amorim. Da universalização do ensino fundamental ao desafio de democratizar o ensino médio em 2016: o que evidenciam as estatísticas? 2011. In: Revista Brasileira Estudos Pedagógicos, Brasília, v. 92, n. 231, p. 268-284, maio/ago. 2011.

NOGUEIRA-MARTINS, Maria Cezira Fantini; BÓGUS, Cláudia Maria. Considerações sobre a metodologia qualitativa como recurso para o estudo das ações de humanização em saúde. Saúde e Sociedade. v. 3, no 3, 2004. Disponível em: < http://www.scielo.br/pdf/sausoc/v13n3/06.pdf >. Acesso em: 18/04/2015.

PAIVA, Angela Randolpho; BURGOS, Marcelo Baumann (Orgs.). A escola e a favela. Rio de Janeiro: PUC-Rio: Ed. Pallas, 2009.

RAUL, Jessica Mara. Mulheres negras, movimentos sociais e direito à cidade: uma perspectiva para as políticas públicas. In: RIBEIRO, Luiz César de Queiroz [et alli]. Emetropolis. Revista eletrônica de Estudos Urbanos e Regionais. n. 22. Rio de Janeiro: Observatório das Metrópoles, 2015. Disponível em:

http://emetropolis.net/system/edicoes/arquivo_pdfs/000/000/022/original/emetropoli s_n22.pdf?1447896390

Mulheres negras e a luta por igualdade: por um feminismo negro decolonial. In: Estudos de Sociologia - Dossiê: Colonialidade, subalternidade e identidades. v.21, n.41, UNESP: São Paulo, 2016. pp.291-302. Disponível em: http://seer.fclar.unesp.br/estudos/article/view/8663/6060

RIBEIRO, Darcy. Classe, cor e preconceito. In: O povo brasileiro: a formação e o sentido do Brasil. São Paulo: Companhia das Letras, 2006.

RIBEIRO, Luiz Cesar de Queiroz; KAZTMAN, Ruben (Orgs.). A cidade contra a escola? Segregação urbana e desigualdades educacionais em grandes cidades da América Latina. Rio de Janeiro: Letra Capital: FAPERJ; Montevidéu, Uruguai: IPPES, 2008. Disponível em: < http://www.observatoriodasmetropoles.net/index.php?option=com_abook\&view=boo $\mathrm{k} \&$ catid $=1 \% 3$ Alivros\&id $=87 \% 3 \mathrm{Aa}$-cidade-contra-a-escola\&Itemid=123\&lang=pt $\#>$. Acesso em: 20/09/2016.

ROLNIK, Raquel. Territórios Negros nas Cidades Brasileiras (etnicidade e cidade em São Paulo e Rio de Janeiro). Disponível em: < https://raquelrolnik.files.wordpress.com/2013/04/territc3b3rios-negros.pdf $>$. Acessado em: 10/08/2015. 
SILVA, Tatiana Dias. Mulheres Negras, Pobreza e Desigualdade de Renda. In: MARCONDES, Mariana Mazzini [et al.] (Orgs.). Dossiê Mulheres Negras. retrato das condições de vida das mulheres negras no Brasil. Brasília: Ipea, 2013.

Educação e população negra: uma análise da última década (1999-2009). In: OLIVEIRA, Iolanda (Org.). Relações raciais no contexto social, na educação e na saúde: Brasil, Cuba, Colômbia e África do Sul. Rio de Janeiro: Quartet, 2012.

YIN, Robert K. Estudo de caso, planejamento e métodos. Porto Alegre: Bookman, 2001.

Recebido em 20 de agosto de 2017. Aceito em 09 de fevereiro de 2018. 